\title{
Manfaat Data External Causes dan Aplikasi ArcGIS di PT Jasa Raharja (Persero) Kantor Cabang DIY
}

\author{
Defin Merlinesia ${ }^{1}$, Nuryati ${ }^{2}$ \\ DIII Rekam Medis Sekolah Vokasi Universitas Gadjah Mada1,2 \\ defin.merlinesia@mail.ugm.ac.id ${ }^{1}$, nur3yati@yahoo.com²
}

\begin{abstract}
Abstrak
Latar belakang: Januari-Agustus 2014 tercatat 614 kejadian kecelakaan lalu lintas (KLL) di Kabupaten Sleman dan jumlah kendaraannya tertinggi di provinsi Daerah Istimewa Yogyakarta (DIY). Pada KMK No 377 Tahun 2007 kompetensi perekam medis mengenai pengolahan data yaitu manajemen rekam medis informasi kesehatan, dan statistik kesehatan. Pendokumentasian dan pengolahan data external causes (EC) fasyankes sangat minim. Ketidaklengkapan ditemukan di RSUP Dr. Sardjito Yogyakarta dan inputnya pada Sistem Informasi Manajemen Rumah Sakit (SIMRS) belum baik. Data EC KLL yang lengkap dibutuhkan untuk urusan jaminan lembaga asuransi seperti PT Jasa Raharja.

Tujuan: Mengetahui manfaat data EC KLL bagi PT Jasa Raharja (Persero) Kantor Cabang DIY, melakukan pemetaan kejadian KLL di Kabupaten Sleman dengan menggunakan software ArcGIS 10.1, dan mengetahui tingkat kejadian KLL Kabupaten Sleman.

Metode: Penelitian desktiptif kualitatif rancangan fenomenologis. Subjeknya petugas Ajun Arsiparis, PA Pelayanan Klaim, dan Kepala Unit Operasional. Teknik pengambilan data adalah studi dokumentasi, observasi, dan wawancara.

Hasil: Manfaat data EC yaitu entry data ke aplikasi pelayanan, pembuatan data/statistik, acuan penjaminan, dan pencegahan KLL. Peta kejadian KLL mendapat tanggapan positif petugas. 341 korban KLL selama JuliDesember 2015 ditangani fasyankes Kabupaten Sleman.

Kesimpulan: Data EC KLL PT Jasa Raharja (Persero) Kantor Cabang DIY secara optimal dan rutin dimanfaatkan petugas untuk entry data ke aplikasi pelayanan, pembuatan data/statistik, acuan penjaminan, dan pencegahan KLL. Data EC belum dimanfaatkan untuk pemetaan KLL. Pemetaan kejadian KLL menggunakan software ArcGIS 10.1 mudah, hasilnya bagus dan berguna. Tingkat KLL di Kabupaten Sleman cenderung menurun.
\end{abstract}

Kata kunci: Manfaat, external causes, ArcGIS.

\begin{abstract}
Background: January-August 2014 on Sleman District noted 614 road traffict accidents (RTA's), highest vehicle amount in Daerah Istimewa Yogyakarta Province. On KMK Number 377 Year 2007 medical recorder competency about data processing such as medical record health information management and health statistic. Health care EC data documentation and processing is very lack. Incomplete EC is found in RSUP Dr. Sardjito Yogyakarta, input to Hospital Information management system (HIMS) has not good. Insurance agency such as PT Jasa Raharja needs complete EC data.

Objective: Knowing about RTA EC data benefits for PT Jasa Raharja (Persero) Branch Office DIY, RTA scene mapping in Sleman District using ArcGIS 10.1 software, and knowing about RTA scene degree in Sleman District.

Methods: Qualitative descriptive research with fenomenologic design. Subjects are Archivist Ajun, Claim Service Administation Technician, and Operational Unit Chairman. Data retrieval techniques are documentation studies, observation, and interview.

Results: Data EC benefits are data entry into application services, data making/statistics, insurance reference, and RTA prevention. RTA scene map obtain positive officers response. 341 victims from JulyDecember 2015 cared by health care in Sleman District.

Conclusion: PT Jasa Raharja (Persero) Branch Office DIY RTA EC data optimally and routinely used by officer such as service application data entry, data making/statistic, insurance reference, and RTA prevention. EC data are not used for mapping yet. RTA mapping using ArcGIS 10.1 software is easy, good and useful output. Sleman District RTA scene degree disposed decrease.
\end{abstract}

Keywords: Benefit, external causes, ArcGIS 


\section{PENDAHULUAN}

Dalam Rencana Umum Nasional Keselamatan (RUNK) Jalan 2011-2035, World Health Organization (WHO) mempublikasikan kematian akibat kecelakaan di jalan sebagai salah satu penyakit tidak menular dengan jumlah kematian tertinggi. Pada tahun 2030, kecelakaan lalu lintas (KLL) di jalan diperkirakan akan menjadi penyebab kematian nomor lima di dunia setelah penyakit jantung, stroke, paru-paru, dan infeksi saluran pernapasan. Perkiraan tersebut dipengaruhi faktor peningkatan jumlah penggunaan kendaraan dan kepatuhan berlalu lintas.

Badan Penelitian dan Pengembangan Kesehatan (Balitbangkes) Kementerian Kesehatan Republik Indonesia (RI) telah melakukan survei penyebab kematian berskala nasional berdasarkan data kematian selama tahun 2014 sebanyak 41.590 jiwa. Urutan ke-delapan adalah akibat KLL.

Profil Kesehatan Provinsi Daerah Istimewa Yogyakarta (DIY) tahun 2012 pada saat ini memperlihatkan pola penyakit pada semua golongan umur telah mulai didominasi oleh penyakit-penyakit degeneratif, terutama penyakit yang disebabkan oleh kecelakaan, neoplasma, kardiovaskuler dan Diabetes Mellitus. Sedangkan Profil Kesehatan Provinsi DIY Tahun 2013 dampak peningkatan volume kendaraan dan perilaku pengendara juga terjadi pada tingkat risiko kecelakaan yang semakin tinggi.

Direktorat Lalu Lintas Provinsi DIY mencatat 2.237 kali kejadian KLL pada bulan Januari-Agustus 2014. Kejadian tersebut tersebar di lima Kepolisian Resor Kota (Polresta), yakni Polresta Yogyakarta sebanyak 290 kejadian, Polresta Bantul sebanyak 807 kejadian, Polresta Kulon Progo sebanyak 279 kejadian, Polresta Gunung Kidul sebanyak 247 kejadian, dan Polresta Sleman sebanyak 614 kejadian.

Laporan Status Lingkungan Hidup Daerah (SLHD) DIY tahun 2013 tercatat dari tahun 2010 sampai 2012 jumlah kendaraan yang mempunyai plat DIY meningkat, dapat berakibat pada meningkatnya angka kecelakaan. Jumlah kendaraan di Kabupaten Sleman paling tinggi diantara
Kabupaten lain di DIY. Menurut SLHD Kabupaten Sleman tahun 2013 terdaftar sebanyak 547.954 buah kendaraan bermotor dimana 459.270 buah merupakan sepeda motor. Sedangkan dalam SLHD Kabupaten Bantul hanya 41.945 buah kendaraan bermotor dimana 36.558 buah merupakan sepeda motor.

Pada KMK No 377 Tahun 2007 terdapat kompetensi perekam medis mengenai pengolahan data menjadi informasi kesehatan yaitu manajemen rekam medis dan informasi kesehatan. Perekam medis mampu mengelola rekam medis dan informasi kesehatan untuk memenuhi kebutuhan pelayanan medis, administrasi dan kebutuhan informasi kesehatan sebagai bahan pengambilan keputusan di bidang kesehatan. Dan kompetensi lain seperti statistik kesehatan dimana perekam medis mampu menggunakan statistik kesehatan untuk menghasilkan informasi dan perkiraan (forcasting) yang bermutu sebagai dasar perencanaan dan pengambilan keputusan di bidang pelayanan kesehatan. Perekam medis harus memastikan kelengkapan data sebelum diolah dan menyajikan informasi kesehatan dimana salah satunya adalah data external causes.

Dari pengalaman praktek kerja lapangan (2014-2015) dan kerja pengabdian (2015) peneliti menjumpai bahwa pendokumentasian data external causes di Rumah Sakit dan Puskesmas sangat minim. Pengolahan datanya menjadi informasi kesehatan juga minim, di Rumah Sakit hanya untuk membuat laporan RL. Ketidaklengkapan pengisian external causes di fasilitas pelayanan kesehatan (fasyankes) ditemukan di RSUP Dr. Sardjito Yogyakarta berdasarkan penelitian Putra (2013) dimana 1933 pasien gawat darurat kasus KLL tahun 2011 belum diimbangi dengan pendokumentasian yang lengkap dan pelaksanaan input data external causes pada Sistem Informasi Manajemen Rumah Sakit (SIMRS) belum baik. Data external causes KLL yang lengkap dibutuhkan dalam urusan penjaminan lembaga asuransi seperti PT Jasa Raharja. Ketidaklengkapan menyebabkan klaim tidak dapat diproses. 
Data yang lengkap umumnya ada pada lembaga asuransi.

Menurut Pardede dan Warnars (2010) Sistem Informasi Geografis (SIG) sangat berguna membantu pengambilan keputusan sebab mampu mengelola dan menganalisis data parsial dan tekstual. Sehingga informasi yang dihasilkan tidak hanya tekstual atau deskriptif tapi dapat diketahui informasi lokasinya. Pada penelitian Yunawati (2015) di Dinas Kesehatan DIY telah dapat dibangun SIG dengan software ArcGIS untuk pengolahan data surveillans penderita HIV/AIDS yang menampilkan peta persebaran HIV/AIDS berdasarkan kelompok umur, jenis kelamin, faktor resiko, dan hubungan antara ketiga indikator. Pembangunan SIG dengan software ArcGIS 10.1 tersebut dapat memvisualisasikan data surveillans penderita HIV/AIDS menjadi lebih informatif. Setelah dilakukan pembangunan SIG ArcGIS 10.1 ini petugas dapat mengolah data menjadi informasi yang diperlukan manajer dan memudahkan manajer dalam pengambilan keputusan.

Berdasarkan studi pendahuluan pada 17 Desember 2015 di PT Jasa Raharja (Persero) Kantor Cabang DIY, terdapat data external causes KLL yang lengkap dari Laporan Polisi (LP). Petugas hubungan masyarakat menyatakan bahwa pengolahan data kecelakaan hanya sebatas diinput ke sistem informasi dan adanya kepentingan untuk klaim. Sedangkan pengolahan datanya belum menggunakan SIG.

Manfaat penelitian ini bagi PT Jasa Raharja (Persero) Kantor Cabang DIY adalah mengaplikasikan pemetaan kejadian kecelakaan lalu lintas dengan menggunakan software ArcGIS 10.1 dan menggunakan pemetaan kejadian KLL untuk pengambilan keputusan.

\section{METODE}

Penelitian ini dilakukan dengan metode penelitian kualitatif deskriptif dan desain penelitian fenomenologis. Subjek penelitian ini adalah petugas Ajun Arsiparis, Pelaksana Administrasi (PA) Pelayanan Klaim, dan Kepala Unit
Operasional PT Jasa Raharja (Persero) Kantor Cabang DIY. Objeknya adalah lembar dalam berkas santunan yang berisi data external causes KLL yang terjadi pada Juli-Desember 2015 di Kabupaten Sleman Yogyakarta. Jumlah berkas santunan adalah 341 berkas.

Teknik pengambilan data menggunakan studi dokumentasi, observasi, dan wawancara. Pelaksanaan dalam analisis data antara lain reduksi data, penyajian data, dan verifikasi.

\section{HASIL DAN PEMBAHASAN}

Data external causes berasal dari berkas santunan pada lembar Laporan Polisi (LP), 'Keterangan Kesehatan Korban Akibat Kecelakaan' atau SKM, 'Keterangan Singkat Kejadian Kecelakaan', dan 'Formulir Pengajuan Santunan'. Dari studi dokumentasi, observasi, dan wawancara diketahui manfaat data external causes antara lain entry data dalam aplikasi pelayanan "DASIJR", pembuatan data/statistik, acuan dalam penjaminan, dan acuan dalam pencegahan kecelakaan lalu lintas.

Entry data ke dalam aplikasi pelayanan "DASIJR" ini sesuai dengan Kristanto (2007) yang menyatakan sebuah sistem informasi adalah kumpulan perangkat keras dan perangkat lunak komputer serta perangkat manusia yang akan mengolah data dengan menggunakan perangkat keras dan perangkat lunak tersebut. Data yang diinput ke dalam sistem informasi dapat berupa formulirformulir, prosedur-prosedur, dan bentuk data lain.

Pembuatan data/statistik yang dilakukan adalah pembuatan laporan bulanan (LB) berupa tabel. Hal ini sesuai dengan Ika (2000) yang menyatakan data yang diolah menjadi bentuk yang lebih berguna dan lebih berarti bagi yang menerima. Data merupakan sesuatu yang nyata atau setengah nyata yang dapat mengurangi derajat ketidakpastian tentang suatu keadaan atau kejadian.

Acuan dalam penjaminan yaitu data dari kepolisian dan fasyankes langsung ada tindak lanjut dari PT Jasa Raharja (Persero) Kantor Cabang DIY untuk mengecek ke fasyankes. Kemudian 
ditentukan korban terjamin atau tidak, jika terjamin dibuatkan guarantee letter atau surat jaminan sehingga biaya perawatan ditanggung PT Jasa Raharja (Persero) Kantor Cabang DIY sesuai ketentuan. Hal ini sesuai dengan Huffman (1994) yang menyatakan rekam medis (data external causes) mempunyai manfaat dalam penggantian biaya. Sebagai bukti klaim asuransi bagi fasyankes dan pasien dan semakin diandalkan untuk membuktikan klaim yang ditagih kepada pihak ketiga. Fasyankes menggunakan data dari rekam medis untuk melaporkan diagnosa atau alasan pengobatan dan tindakan supaya tagihan biaya dapat diajukan dengan benar.

Acuan dalam pencegahan KLL yaitu PT Jasa Raharja (Persero) Kantor Cabang DIY bekerjasama dengan kepolisian untuk mengetahui daerah rawan kecelakaan kemudian melaksanakan pencegahan KLL seperti mengadakan sarana prasarana dan program. Hal ini sesuai dengan Isfandari (2009) yang menyatakan penyediaan informasi sebagai input untuk mengembangkan pencegahan yang tepat untuk memfasilitasi pada kasus orang dengan disabilitas agar dapat berfungsi optimal. Dan sesuai dengan Savedoff dan Smith (2006) statistik pelayanan kesehatan merupakan hal pokok untuk memanajemen pelayanan kesehatan publik, mengindentifikasi tren kesehatan, dan mengalokasikan sumber daya secara efisien.

Untuk pemetaan, peneliti membuat beberapa macam peta kejadian KLL di Kabupaten Sleman Yogyakarta antara lain:

1. Peta Berdasarkan Jenis Kelamin

Peta dibawah ini dibuat berdasarkan klasifikasi jenis kelamin yaitu laki-laki dan perempuan dengan bentuk penyajian diagram lingkaran. Rata-rata keseluruhan fasyankes menangani korban laki-laki lebih banyak daripada perempuan.

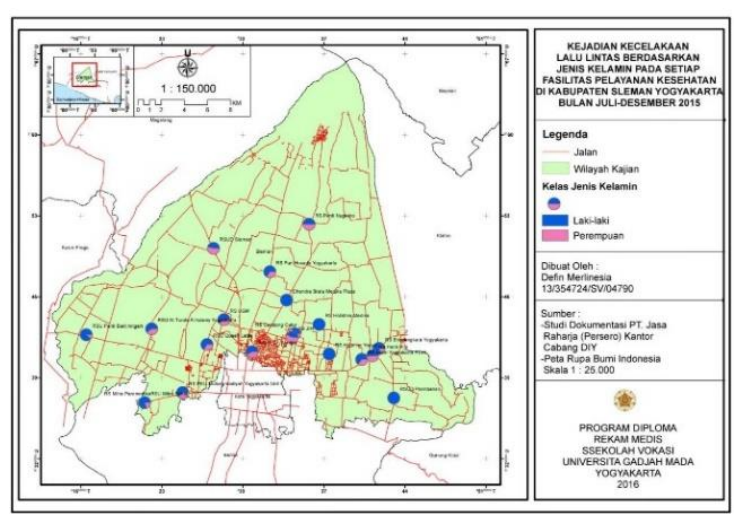

Gambar 1. Peta Kejadian Kecelakaan Lalu Lintas Berdasarkan Jenis Kelamin pada Setiap Fasilitas Pelayanan Kesehatan di Kabupaten

Sleman Yogyakarta Bulan Juli-Desember 2015

2. Peta Berdasarkan Lokasi Kecelakaan Lalu Lintas dan Lokasi Fasyankes

Peta dibawah ini berupa lokasi terjadinya KLL dan lokasi fasyankes di Kabupaten Sleman yang menanganinya. Terdapat 99 lokasi berupa jalan dimana pada peta diatas ditunjukkan jumlah korban yang ada pada lokasi tersebut. Fasyankes berjumlah dua puluh buah. Pada lokasi kecelakaan terdapat informasi jumlah korban kecelakaan di lokasi jalan tersebut, terdapat tiga jalan yang cukup banyak terjadi KLL yaitu jumlah korbannya 36, 34, dan 26 orang.

3. Peta Berdasarkan Jenis Kendaraan

Peta dibawah ini dibuat berdasarkan klasifikasi jens kendaraan yang terdapat 11 macam dari Buku ICD10. Jenis kendaraan disajikan dengan diagram batang atau bar chart.

Dapat diketahui misalnya korban yang ditangani di RSUD Sleman paling banyak statusnya kecelakaan pengguna motor dengan pengguna kendaraan roda 2 atau 3.

4. Peta Berdasarkan Kecamatan

Peta dibawah ini dibuat berdasarkan daerah yaitu kecamatan di Kabupaten Sleman yang terdiri dari 17 Kecamatan (Daftar Nama Padukuhan Se-Kabupaten Sleman Berdasarkan Keputusan Bupati Sleman No.35/Kep.KDH/2001). Penyajian peta tersebut menggunakan fasilitas pada ArcGIS 10.1 yaitu quantities-graduated colors dimana klasifikasi jumlah korban tersebut secara natural breaks dan otomatis tergantung berapa jumlah klasifikasi yang ditentukan. 
Manfaat Data External Causes dan Aplikasi ArcGIS di PT Jasa Raharja...

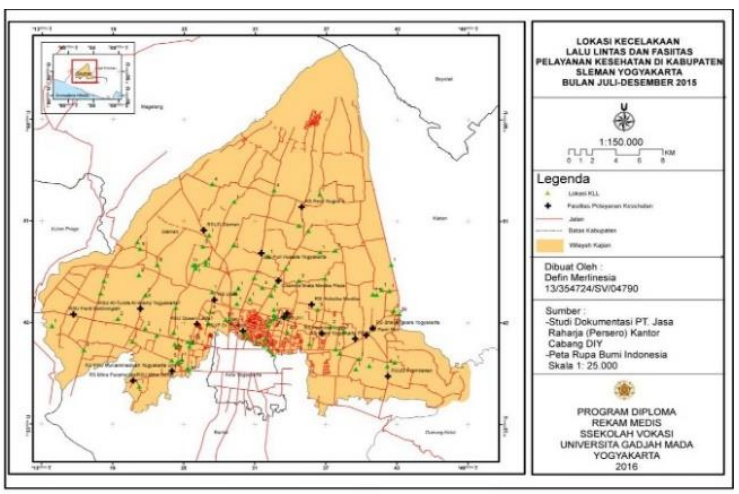

Gambar 2. Peta Lokasi Kecelakaan Lalu Lintas dan Fasilitas Pelayanan Kesehatan di Kabupaten Sleman Yogyakarta Bulan JuliDesember 2015

Dapat dilihat gradasi warna yang menunjukkan tingkat banyaknya korban yang mengalami kecelakaan lalu lintas pada kecematan tersebut. Paling banyak kecelakaan lalu lintas terjadi di Kecamatan Gamping, Mlati, dan Kalasan.

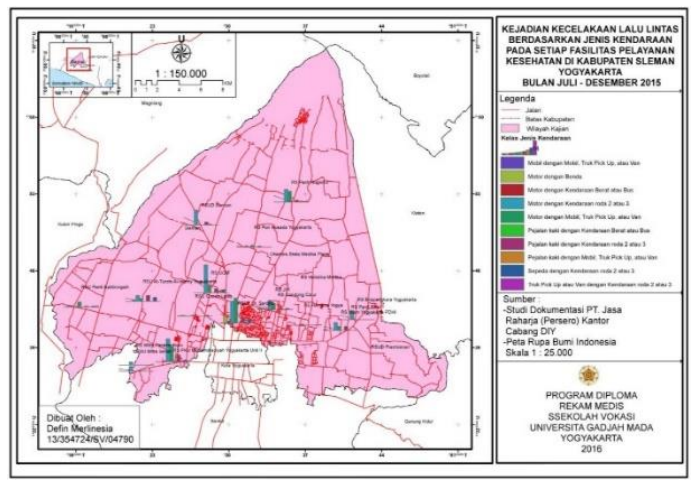

Gambar 3. Peta Kejadian Kecelakaan Lalu Lintas Berdasarkan Jenis Kendaraan pada Setiap Fasilitas Pelayanan Kesehatan di Kabupaten Sleman Yogyakarta Bulan JuliDesember 2015

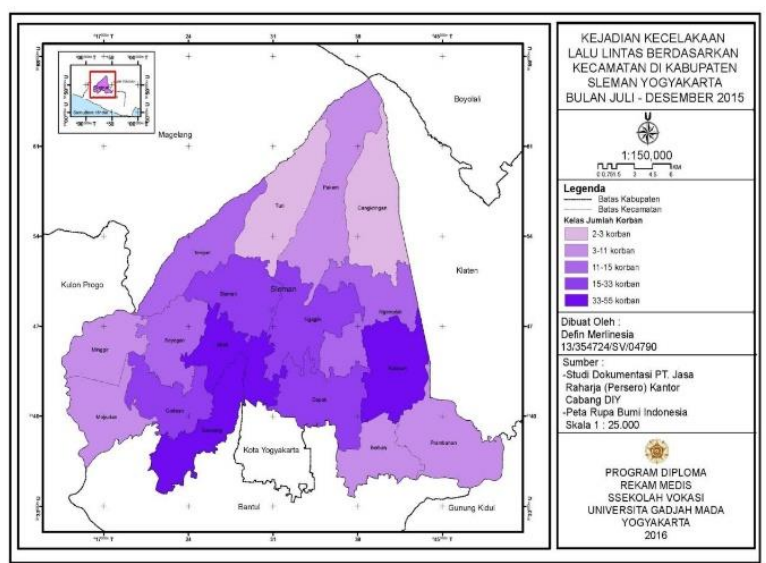

Gambar 4. Peta Kejadian Kecelakaan Lalu

Lintas Berdasarkan Kecamatan di Kabupaten

Sleman Yogyakarta Bulan Juli-Desember 2015

Tanggapan petugas adanya

pemetaan KLL dari segi ketertarikan dan kegunaan yaitu bagus dan berguna. Dari segi kegunaan, terdapat berbagai kegunaan yaitu mengetahui lokasi terjadinya KLL, daerah rawan KLL, fasyankes yang menangani, dan sebagai dasar dalam melakukan pencegahan KLL.

Kegunaan dalam pencegahan adalah perencanaan fasilitas yang menunjang pencegahan KLL sehingga angka kejadian dapat ditekan. Selain itu, dapat diketahui mana fasyankes yang paling banyak menangani korban. PT Jasa Raharja (Persero) Kantor Cabang DIY belum melakukan penyajian informasi kejadian KLL dengan pemetaan. Terdapat kemungkinan untuk penerapan pemetaan dengan software ArcGIS ini namun memerlukan waktu dan petugas yang belum mempunyai kemampuan menggunakannya. Alternatifnya dengan bekerjasama dengan pihak akademik (perguruan tinggi) untuk membuat pemetaan kejadian KLL.

ArcGIS perlu diterapkan, sesuai dengan Savedoff dan Smith (2006) bahwa pentingnya mengumpulkan, memproses, dan menggunakan data dalam usaha meningkatkan kesehatan tidak dapat dipungkiri. Sebagian besar progres dalam memperbesar dan meningkatkan kualitas kehidupan dikarenakan progres teknis, termasuk kemajuan pengetahuan mengenai penyakit dan ketepatan biaya serta hasil yang efektif. Untuk memperluas generasi dan penerapan informasi serta pengetahuan dapat difasilitasi dan menjadi lebih sistematis, progres percepatan berguna meningkatkan kesehatan dan memungkinkan berkurangnya kesenjangan kesehatan. Salah satu fasilitas untuk penyajian informasi kejadian KLL adalah SIG.

SIG bersifat menarik, interaktif, dan menantang dalam usaha untuk peningkatan pemahaman, pembelajaran, dan pendidikan mengenai ide atau konsep ruang, lokasi, kependudukan, dan unsur geografis yang terdapat di atas permukaan bumi (Prahasta, 2014). Pemahaman akan mengarah kepada pengambilan 
Manfaat Data External Causes dan Aplikasi ArcGIS di PT Jasa Raharja...

keputusan, menurut Elly (2009) SIG berperan sebagai alat yang sangat penting dalam pengambilan keputusan karena dapat memberikan informasi pada pengambil keputusan untuk analisis dan penerapan database keruangan.

Environmental Systems Research Institute (ESRI) sebagai provider teknologi SIG di dunia terus melakukan riset dalam pengembangan teknologi yang applicable dan memberikan manfaat sebesar- besarnya bagi pemerintahan dan instansi terkait. Hal ini berguna untuk menunjang kinerja pemerintah dalam pengambilan keputusan dan menghasilkan kebijakan yang bermanfaat bagi masyarakat. PT Jasa Raharja (Persero) sebagai Badan Usaha Milik Negara (BUMN) juga berperan penting sebagai pengambil kebijakan dan pelayanan harus ditunjang dengan meningkatkan. pemanfataan teknologi Pada situs PT Jasa Raharja Direktur Utama PT Jasa Raharja menyatakan pada tahun 2015 PT Jasa Raharja berusaha meningkatkan pemanfataan teknologi informasi dan komunikasi berupa host to host data korban KLL antara Jasa Raharja dengan Rumah Sakit.

Jika penggunaan ArcGIS diterapkan baik di PT Jasa Raharja (Persero) daerah maupun pusat akan cocok dan dapat dilakukan. PT Jasa Raharja (Persero) pusat lebih bagus teknologinya. Penerapan pemetaan dengan ArcGIS sangat mungkin dilakukan dari tingkat pusat. Berdasarkan 'Program Pengembangan Sistem Informasi Geografis (SIG) Pemerintahan Daerah: Menuju Percepatan Pembentukan Simpul Jaringan NSDI (Amanat UndangUndang No.4/2011)' terdapat tahapan program penggunaan teknologi ArcGIS.

Tiga tahapan program yang ditawarkan ESRI Indonesia untuk mendukung Pemerintah Daerah Provinsi/Kabupaten/Kota dalam penggunaan Teknologi ArcGIS terdiri dari:

\section{Analisa Kebutuhan (Baseline Survey)}

2. Tahap Implementasi Program

a. Instalasi dan Pelatihan

Diperlukan pengadaan

perangkat Sistem Informasi Geografis juga dilengkapi dengan setup, instalasi, dan konfigurasi system. Selain itu diadakan kegiatan pengembangan kapasitas Sumber Daya Manusia (SDM) berupa pelatihan teknis (Training of Trainers) dan workshop.

b. Indonesia User Conference Merupakan agenda tahunan yang diadakan oleh PT ESRI Indonesia bertujuan untuk meningkatkan peran SIG dalam pembangunan nasional Indonesia.

3. Diseminasi (Strategi Keberlanjutan Program)

PT ESRI Indonesia sebagai pemrakarsa program bekerjasama dengan Pemerintah Daerah Provinsi/Kabupaten/Kota telah menetapkan rencana strategi untuk memastikan keberlanjutan program.

Menurut Aziz dan Pujiono (2006) lingkup pekerjaan dalam representasi SIG antara lain:

1. Input (pemasukan)

Pada tahap ini dilakukan konversi dahulu kedalam format digital yang sesuai. Proses konversi tersebut dikenal dengan proses digitasi (digitizing);

\section{Manipulation}

Manipulasi data adalah proses editing data yang telah diinput, berguna untuk menyesuaikan tipe dan jenis data supaya sesuai dengan sistem yang dibuat. Seperti perubahan proyeksi, penyesuaian skala peta, agregasi data dan generalisasi;

3. Proses

Proses yang dimaksud merupakan semua kegiatan pengolahan dan penyimpanan data ke dalam database (basis data); 
4. Query

Kemampuan paling mendasar dari SIG adalah untuk menjawab berbagai pertanyaan yang lazim dikemukakan oleh para eksekutif dalam rangka menghadapi fenomena, masalah, peristiwa, atau cara bertindak, meliputi pertanyaan: apa, siapa, bilamana, dimana, dan berapa. Seluruh pertanyaan tersebut dapat terjawab dengan menggunakan peta atau lokasi penyebaran geografis serta keterangan yang diminta. Adapun untuk menjawab pertanyaan bagaimana dan mengapa, akan didapat dari proses pengolahan dan hasil analisis program SIG;

5. Analisis

Secara general, SIG terdapat dua jenis fungsi analisis yaitu fungsi analisis spasial dan fungsi analisis atribut. Fungsi analisis spasial adalah operasi yang dilakukan pada data spasial. Data spasial adalah data yang berhubungan dengan ruang/bersifat keruangan. Contoh pada fungsi analisis spasial adalah classification (mengklasifikasikan ketinggian suatu obyek), Network (merujuk pada titik atau garis sebagai satu kesatuan jaringan yang tak terpisahkan), overlay (fungsi analisis untuk setiap layer, untuk menghasilkan data spasial yang baru dari beberapa data spasial yang ada), dan masih banyak lagi. Fungsi analisis atribut adalah fungsi pengolahan data atribut, yaitu yang tidak berhubungan dengan ruang. Contohnya adalah pada pengolahan database (membaca, menulis, menyimpan data) juga pada perluasan operasi database; dan

6. Visualization

Output dari SIG adalah penyajian data dalam sebuah peta yang dilengkapi dengan atribut peta dan atribut data lainnya.

Menurut Susilo (2016) terkait kendala untuk menerapkan dari segi
Sumber Daya Manusia (SDM) dapat dilakukan dengan pelatihan. SDM adalah modal dasar pembangunan nasional maka kualitasnya harus dikembangkan dan diarahkan supaya dapat mencapai tujuan yang diharapkan. Untuk mewujudkan visi dan misi maka organisasi dapat memanfaatkan SDM seoptimal mungkin agar memberikan added value. Salah satu metode pengembangan SDM yaitu dengan meningkatkan kompetensi individu yang bisa melalui perencanaan dan pengembangan SDM. Menurut Sirait (2006) pengembangan. SDM meliputi pelatihan (training) guna meningkatkan keterampilan dalam melaksanakan pekerjaan tertentu dan pendidikan guna meningkatkan pengetahuan umum dan pemahaman atas keseluruhan lingkungan. Dalam penerapan pemetaan dengan ArcGIS, juga perlu didukung adanya Tupoksi (Tugas Pokok dan Fungsi) dan SOP. Dalam Pedoman Penyusunan Standar Operasional Prosedur Administrasi Pemerintahan Permenpan tahun 2012, pengertian Standar Operasional Prosedur (SOP) adalah serangkaian instruksi tertulis yang dibakukan mengenai berbagai proses penyelenggaraan aktivitas organisasi, bagaimana dan kapan harus dilakukan, dimana dan oleh siapa dilakukan. SOP bersifat mengikat yaitu harus mengikat pelaksana dalam melaksanakan tugasnya sesuai dengan prosedur standar yang telah ditetapkan. Penerapan SOP pada unit kerja mempunyai peran strategis dan yang sangat unggul. Hal ini dikarenakan memberikan dampak peningkatan efisiensi pada tiap proses kerja. Itu sebabnya SOP sangat direkomendasikan (Budihardjo, 2014). Tugas adalah salah satu elemen penting pada suatu organisasi. Agar terwujud pencapaian tujuan organisasi secara efektif dan efisien, tugas-tugas yang ada harus dirancang dengan benar dan dijabarkan dengan jelas. Pelaksanaan tugas-tugas tersebut berdasar atas tugas pokok dan fungsi 
Manfaat Data External Causes dan Aplikasi ArcGIS di PT Jasa Raharja...

(Tupoksi) organisasi. Tingkat kejadian KLL diketahui dari pengolahan data KLL yang terjadi pada tahun 2015 dari bulan Juli sampai Desember di Kabupaten Sleman Yogyakarta. Peneliti mengolah data tersebut ke dalam Microsoft Excel 2007, diketahui bahwa terdapat 341 kejadian KLL selama bulan Juli-Desember 2015. Berikut ini prosentase tingkat kejadiannya:

Tabel 1. Prosentase Kejadian Kecelakaan

Lalu Lintas Berdasarkan Fasyankes di Kabupaten Sleman Yogyakarta Bulan Juli Desember 2015

\begin{tabular}{|c|c|c|c|}
\hline & Fasyankes & Jumlah & $\%$ \\
\hline 1 & $\begin{array}{lll}\text { Chandra } & \text { Brata } & \text { Medika } \\
\text { Plaza } & & \\
\end{array}$ & 1 & 0.29 \\
\hline 2 & $\begin{array}{ll}\text { RS } & \text { Bhayangkara } \\
\text { Yogyakarta } & \end{array}$ & 9 & 2.64 \\
\hline 3 & RS Condong Catur & 3 & 0.88 \\
\hline 4 & RS Hermina Yogya & 1 & 0.29 \\
\hline 5 & $\begin{array}{l}\text { RS Islam Yogyakarta } \\
\text { PDHI }\end{array}$ & 17 & 4.99 \\
\hline 6 & RS JIH & 19 & 5.57 \\
\hline 7 & RS Panti Nugroho & 26 & 7.62 \\
\hline 8 & RS Panti Rini & 31 & 9.09 \\
\hline 9 & $\begin{array}{l}\text { RS PKU Muhammadiyah } \\
\text { Yogyakarta Unit II }\end{array}$ & 49 & 14.37 \\
\hline 10 & $\begin{array}{l}\text { RS Puri Husada } \\
\text { Yogyakarta }\end{array}$ & 3 & 0.88 \\
\hline 11 & RS Holistika Medika & 1 & 0.29 \\
\hline 12 & RS UGM & 44 & 12.90 \\
\hline 13 & $\begin{array}{l}\text { RSU At-Turots Al-Islamy } \\
\text { Yogyakarta }\end{array}$ & 20 & 5.87 \\
\hline 14 & RS Mitra Paramedika & 3 & 0.88 \\
\hline 15 & RSU Mitra Sehat & 5 & 1.47 \\
\hline 16 & RSU Panti Baktiningsih & 9 & 2.64 \\
\hline 17 & RSU Queen Latifa & 3 & 0.88 \\
\hline 18 & RSUD Prambanan & 4 & 1.17 \\
\hline 19 & RSUD Sleman & 26 & 7.62 \\
\hline \multirow[t]{2}{*}{20} & RSUP Dr. Sardjito & 67 & 19.65 \\
\hline & TOTAL & 341 & 100 \\
\hline
\end{tabular}

Sumber: PT Jasa Raharja (Persero) Kantor Cabang DIY

Selama bulan Juli-Desember 2015, sebanyak 341 kejadian KLL terjadi di Kabupaten Sleman ditangani oleh dua puluh fasyankes. Fasyankes yang menangani korban KLL paling banyak adalah RSUP Dr. Sardjito yaitu 67 orang korban dengan prosentase 19,65\%. Terdapat tiga fasyankes yang menangani satu orang korban saja (paling sedikit) dengan prosentase $0,29 \%$ yaitu Chandra
Brata Medika Plaza, RS Hermina Yogya, dan RS Holistika Medika.

Tabel 2. Prosentase Kejadian Kecelakaan Lalu Lintas Berdasarkan Kecamatan di Kabupaten Sleman Yogyakarta Bulan Juli-Desember 2015

\begin{tabular}{rlcc} 
NO & KECAMATAN & JUMLAH & $\%$ \\
\hline 1 & Berbah & 10 & 2,93 \\
2 & Cangkringan & 3 & 0,88 \\
3 & Depok & 33 & 9,68 \\
4 & Gamping & 55 & 16,13 \\
5 & Godean & 27 & 7,92 \\
6 & Kalasan & 42 & 12,32 \\
7 & Minggir & 7 & 2,05 \\
8 & Mlati & 41 & 12,02 \\
9 & Moyudan & 11 & 3,23 \\
10 & Ngaglik & 23 & 6,74 \\
11 & Ngemplak & 15 & 4,40 \\
12 & Pakem & 10 & 2,93 \\
13 & Prambanan & 10 & 2,93 \\
14 & Seyegan & 13 & 3,81 \\
15 & Sleman & 27 & 7,92 \\
16 & Tempel & 12 & 3,52 \\
17 & Turi & 2 & 0,59 \\
\hline & TOTAL & 341 & 100 \\
\hline
\end{tabular}

Sumber: PT Jasa Raharja (Persero) Kantor Cabang DIY

Dari seluruh kecamatan, kejadian KLL tertinggi terjadi di Kecamatan Gamping sebesar 55 kejadian dengan prosentase $16,13 \%$. Sedangkan kejadian KLL di Kecamatan Turi adalah terendah sebesar 2 kejadian dengan prosentase 0,59\%. Berdasarkan data Direktorat Lalu Lintas Provinsi DIY, jumlah KLL paling banyak kedua di Kabupaten Sleman. Jumlah kendaraan Kabupaten Sleman paling tinggi diantara Kabupaten lain di DIY. Laporan Status Lingkungan Hidup Daerah (SLHD) tahun 2013 tercatat dari tahun 2010-2012 jumlah kendaraan yang mempunyai plat DIY meningkat, dapat berakibat meningkatnya angka kecelakaan. Sebanyak 341 kejadian selama enam bulan pada tahun 2015 tergolong lebih rendah dibandingkan 614 kejadian selama delapan bulan pada tahun 2014. Jika dirata-rata maka setiap bulan di tahun 2015 hampir terjadi 57 kejadian sedangkan setiap bulan di tahun 2014 hampir terjadi 77 kejadian. 
Hal ini berarti KLL di Kabupaten Sleman cenderung menurun.

Tabel 3. Prosentase Kejadian Kecelakaan Lalu Lintas Berdasarkan Jenis Kelamin di Kabupaten Sleman Yogyakarta Bulan JuliDesember 2015

\begin{tabular}{rlrl}
\hline NO & JENIS KELAMIN & JUMLAH & $\%$ \\
\hline 1 & Laki - laki & 201 & 58,94 \\
2 & Perempuan & 140 & 41,06 \\
\hline & TOTAL & 341 & 100 \\
\hline
\end{tabular}

Sumber: PT Jasa Raharja (Persero) Kantor Cabang DIY

KLL di Kabupaten Sleman selama JuliDesember 2015 menimbulkan korban jiwa laki-laki lebih banyak yaitu 201 jiwa dibandingkan dengan korban jiwa perempuan yaitu 140 jiwa. Hal ini sesuai dengan penelitian Ayuso et al (2015) yang menunjukkan bahwa laki-laki memiliki pola berkendara yang lebih berisiko daripada perempuan. Maka berpengaruh pada kecelakaan sering dialami laki-laki.

\section{PENUTUP}

Kesimpulan dari penelitian ini adalah:

1. Dilakukan pengembangan manfaat data external causes KLL di PT Jasa Raharja (Persero) Kantor Cabang DIY dengan cara petugas Ajun Arsiparis dan PA Pelayanan Klaim menggunakan data tersebut untuk pemetaan kejadian kecelakaan lalu lintas dengan bantuan software ArcGIS.

2. Penggunaan software ArcGIS sebaiknya diterapkan untuk pengolahan data KLL oleh petugas Ajun Arsiparis dan PA Pelayanan Klaim PT Jasa Raharja (Persero) Kantor Cabang DIY.

a. Penerapan pemetaan dengan software ArcGIS sebaiknya dibina dari PT Jasa Raharja pusat.

b. PT Jasa Raharja (Persero) Kantor Cabang DIY mengadakan pelatihan pemetaan dengan software ArcGIS kepada petugas Ajun Arsiparis dan PA Pelayanan Klaim.

c. Kepala Unit Operasional membuat SOP dan menambahkan tugas pemetaan dengan ArcGIS pada 'Uraian Pekerjaan dan Persyaratan Jabatan (Deskripsi Jabatan)' petugas Ajun Arsiparis dan PA Pelayanan Klaim. d. PT Jasa Raharja (Persero) Kantor Cabang DIY melakukan koordinasi dengan Pemerintah Daerah Provinsi DIY dan ESRI Indonesia yang mempunyai program untuk mendukung Pemerintah Daerah Provinsi/Kabupaten/Kota dalam penggunaan teknologi ArcGIS serta memperhatikan lingkup pekerjaan representasi SIG (input, manipulation, proses, query, analisis, dan visualization).

3. Sebaiknya PT Jasa Raharja (Persero) Kantor Cabang DIY mempertahankan dan menekan kejadian KLL agar semakin turun. Perlu dikaji penyebab lebih banyaknya angka kecelakaan yang dialami laki-laki dan hal-hal yang menunjang penurunan kejadian KLL agar bisa diterapkan di kabupaten lain di Provinsi DIY.

\section{DAFTAR PUSTAKA}

Ayuso, M., M. Guillen, dan A.M.P. Marin. (2016). Transportation Research Part C: Using GPS Data to Analyse the Distance Travelled to the First Accident at Fault in Pay-As-You-Drive Insurance. 68 (2016): 160-167.

Aziz, dan Pujiono. (2006). Sistem Informasi Geografis Berbasis Desktop dan Web. Yogyakarta: Gava Media.

Badan Lingkungan Hidup Daerah Istimewa Yogyakarta. Laporan Status Lingkungan Hidup Daerah (SLHD) Tahun 2013. Yogyakarta.

Badan Lingkungan Hidup Daerah Istimewa Yogyakarta. Laporan Status Lingkungan Hidup Daerah (SLHD) Kabupaten Bantul Tahun 2013. Yogyakarta.

Badan Lingkungan Hidup Daerah Istimewa Yogyakarta. Laporan Status Lingkungan Hidup Daerah (SLHD) Kabupaten Sleman Tahun 2013. Yogyakarta.

Dinas Kesehatan Provinsi DIY. (2012). Profil Kesehatan Provinsi DIY Tahun 2012. Yogyakarta: Dinkes Provinsi DIY. Diakses melalui http://dinkes.slemankab.go.id/profildinas-kesehatan-kabupaten-sleman pada 16 Mei 2016 pukul 11.30 WIB.

Elly, M.J. (2009). Sistem Informasi Geografi: Menggunakan Aplikasi ArcView 3.2 dan ERMapper 6.4. Yogyakarta: Graha Ilmu. 
Huffman, E. (1994). Health Information Management. Berwyn, Illinois: Phiscian's Record Company.

Ika, S. (2000). Analisa Sistem. Diakses melalui http://kuliah.dinus.ac.id/ika/asi.html pada 20 Juni 2016 pukul 12.53 WIB.

Isfandari, S. (2009). Buletin Penelitian Sistem Kesehatan: Manfaat Data Disabilitas Rikerdas Bagi Perencanaan Kesehatan di Indonesia. 12 (3): 268-274.

Kementerian Perhubungan RI. (2011). Rencana Umum Nasional Keselamatan (RUNK) Jalan 2011-2035. Jakarta.

Kristanto, A. (2007). Perancangan Sistem Informasi dan Aplikasinya. Klaten: Gava Media.

Pardede dan Warnars. (2010). Pemanfaatan Teknologi Sistem Informasi Geografis untuk Menunjang Pembangunan Daerah. Jakarta: Universitas Budi Luhur.

Pemerintah Kabupaten Sleman. (2001). Daftar Nama Padukuhan Se-Kabupaten Sleman Berdasarkan Keputusan Bupati Sleman No.35/Kep.KDH/2001. 2001. Diakses melalui http://www.slemankab.go.id/wilayahadministratif pada 17 Juni 2016 pukul 12.25 WIB.

Prahasta, E. (2014). Sistem Informasi Geografis (Konsep-Konsep Dasar Perspektif Geodesi \& Geomatika). Bandung: Informatika.

PT Jasa Raharja (Persero). (2014). Pesan Direktur Utama. Diakses melalui http://www.jasaraharja.co.id/tentangkami/pesan-direktur-utama pada 16 Mei 2016 pukul 10.00 WIB.

Putra, R.H.B. (2014). Kajian Kelengkapan Data External Causes pada SIMRS Gawat Darurat Pasien Kasus Kecelakaan Lalu Lintas untuk Pembuatan Laporan RL 4b (Penyebab Cedera) di RSUP Dr. Sardjito Yogyakarta.Tugas Akhir. Fakultas Sekolah Vokasi Universitas Gadjah Mada, Yogyakarta.

Savedoff, W.D., dan Anne-Marie Smith. (2006). Priorities in Health. Washington DC: The World Bank.

Sirait, J.T. (2006). Memahami Aspek-Aspek Pengelolaan Sumber Daya Manusia dalam Organisasi. Jakarta: Gramedia Widiasarana Indonesia. pada 10 Juni 2016 pukul 14.21 WIB.

Susilo, H. (2016). Konsep dan Peran Perencanaan Pengembangan Sumber Daya Manusia. Diakses melalui http://herususilofia.lecture.ub.ac.id pada 15 Juni 2016 pukul 09.30 WIB.

Yunawati, N.P.L. (2015). Membangun Sistem Informasi Geografis Pengolahan Data Surveillans HIV/AIDS dengan Menggunakan ArcGIS di Dinas Kesehatan Daerah Istimewa Yogyakarta. Tugas Akhir. Fakultas Sekolah Vokasi Universitas Gadjah Mada, Yogyakarta.

80 Defin Merlinesia 